\title{
Neutrophil/Lymphocyte Ratio and Prognosis in Patients with Non-Metastatic Nasopharyngeal Cancer: A Single-Center Experience
}

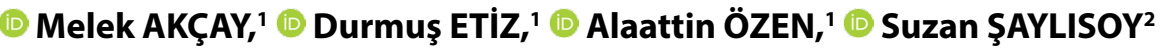 \\ 'Department of Radiation Oncology, Eskişehir Osmangazi University Faculty of Medicine, Eskişehir-Turkey \\ ${ }^{2}$ Department of Radiology, Eskişehir Osmangazi University Faculty of Medicine, Eskişehir-Turkey
}

\begin{abstract}
OBJECTIVE
Nasopharyngeal cancer's presentation and prognosis are variable. Even patients with the same clinical stage can have very different prognoses. The aim of the present study was to investigate clinical outcomes and prognosis, especially the effects of neutrophil/lymphocyte ratio (NLR), of non-metastatic nasopharyngeal carcinoma (NPC) in patients receiving radiotherapy (RT) \pm chemotherapy (CT) between March 2006 and August 2017 in the Eskişehir Osmangazi University Medical Faculty of Radiation Oncology Department.

\section{METHODS}

Sixty-two patients with non-metastatic NPC treated with RT \pm CT were retrospectively evaluated. Patient characteristics, such as age, gender, Karnofsky Performance Status (KPS), T phase, N phase, tumor, lymph node, and metastasis phase, histopathologic subgroup, tumor size, NLR, and hemoglobin value, and treatment characteristics, such as concurrent/adjuvant CT status, RT intermission time, and RT total time, were investigated.
\end{abstract}

\section{RESULTS}

Median overall survival (OS) was 55 (10-134) months, whereas median disease-free survival was 44 (6-129) months. The median duration of local control was 48 (6-129) months. Eleven (17.7\%) patients developed distant metastases. Distant metastases were detected in $6(9.7 \%)$ patients who had local control. Statistically significant results were obtained between general survival and sex ( $\mathrm{p}=0.015)$, KPS $(p<0.001)$, and NLR $(p<0.001)$. Distant metastases were found to be significantly higher in male cases, and all 11 metastatic cases were male (Fisher's exact test, $\mathrm{p}=0.012$ ).

\section{CONCLUSION}

Patients with high NLR had lower OS, and pretreatment NLR value may be a guide in determining which patients should receive more aggressive treatment.

Keywords: Nasopharyngeal carcinoma; neutrophil/lymphocyte ratio; prognosis; radiotherapy. Copyright ๑ 2019, Turkish Society for Radiation Oncology

\section{Introduction}

The prevalence of nasopharyngeal carcinoma (NPC) varies by race/ethnicity and geographic location.[1] Radiotherapy (RT) \pm chemotherapy (CT) is the stan- dard treatment for NPC because of its anatomical location and its radiosensitivity.[2] Currently, the prognosis of patients with NPC is primarily evaluated using the tumor, lymph node, and metastasis (TNM) staging system, although in some patients there are inconsis- 
tencies between TNM stages and clinical outcomes.[3] Patients at the same TNM stage show different survival outcomes because the TNM system does not reflect biological heterogeneity.[3,4] To date, plasma cell-free Epstein-Barr virus (EBV) DNA titer remains the only biomarker with clinical utility in NPC.[4-6] Thus, there is a critical need for additional biomarkers for prognostication and precise treatment stratification in patients with this disease. Recently, several studies have reported the association of elevated pretreatment neutrophil/ lymphocyte ratio (NLR) with adverse prognoses in multiple tumor types. $[7,8]$ Cancer-associated inflammation has a well-established etiologic link with malignancy.[6] The dynamic crosstalks among immune cells, inflammatory proteins, and cytokines in the tumor microenvironment and systemic circulation are important factors contributing to tumorigenesis and cancer's proliferative and invasive properties. The increased inflammatory response that occurs in response to cancer has been found to correlate with negative clinicopathologic predictors in many operable and inoperable neoplasms. [9] Systemic inflammatory response has been shown to promote cancer progression and metastasis by facilitating angiogenesis, inhibiting apoptosis, and damaging DNA.[5] The NLR is an important biomarker that reflects systemic inflammation.[10]

The aim of the present study was to evaluate the prognostic effect of clinical outcomes and treatment characteristics, especially NLR, in non-metastatic NPC patients receiving $\mathrm{RT} \pm \mathrm{CT}$ between March 2006 and August 2017 in our center.

\section{Materials and Methods}

\section{Patient Characteristics}

A total of 62 patients were included in the study. All patients were diagnosed by a pathologist and were treated with radical treatment between March 2006 and May 2017 in the Eskişehir Osmangazi University Medical Faculty of Radiation Oncology Department. All participants had a detailed history and physical examination records. Patients were evaluated retrospectively.

Patients aged between 18 and 80 years with a Karnofsky Performance Status (KPS) score $\geq 60$ and without distant metastasis were included in the study. Pre-existing cases with NPC with RT, multiple cancer diagnosis, and infection at the beginning of treatment were excluded from the study.

Diagnosis and staging of all patients were completed before treatment. NPC was diagnosed by biopsy in endoscopy guide. All patients underwent head and neck magnetic resonance imaging and/or computed tomography, fluorodeoxyglucose-positron emission tomography computed tomography (FDG-PET CT) imaging and, if necessary, magnetic resonance imaging of the brain. Staging was based on the Union for International Cancer Control/American Joint Committee on Cancer $\left(7^{\text {th }}\right.$ Edition) TNM staging system.

\section{Treatment Characteristics}

Ten early-stage cases (T1-T2N0) received RT alone. Two advanced stage cases received RT alone due to age and/ or comorbidities. Fifty cases with local advanced disease received both $\mathrm{RT}$ and concomitant $\mathrm{CT}$. In consideration of the patient's age, KPS, and comorbid diseases, 43 patients were treated with cisplatin $80-100 \mathrm{mg} / \mathrm{m}^{2}$ every three weeks, and seven patients were treated with weekly $40 \mathrm{mg} / \mathrm{m}^{2}$ cisplatin CT regimen. Patients were seen at the clinic at least twice a week. Weekly full blood and blood biochemical controls were performed, and side effects were recorded in our patient tracking system. Forty $(64.5 \%)$ patients were treated with amifostine. The oral intake and weight of the patient were monitored weekly, and oral nutrition solution or intravenous nutritional support was given according to the needs of the patients. Patients were divided into two groups according to their RT modalities as non-intensity-modulated radiotherapy (IMRT) and IMRT groups. Non-IMRT techniques were applied between 2006 and 2013, and IMRT technique was applied to all patients from 2014 to 2017.

\section{Statistical Analysis}

Data were analyzed using SPSS 22.0 (released 2013, IBM SPSS Statistics for Windows, version 22.0; IBM Corp., Armonk, NY, USA). Data are expressed as mean \pm standard error and number and percentage. Shapiro-Wilk test was used to evaluate the normality of the distribution. Variance analysis (ANOVA) was used to determine the differences between group averages, and Tukey's test was used for post hoc tests to determine the differences. Chi-square test was used in the analysis of the generated cross tables. KaplanMeier test was used to compare the mean life span, and the log-rank test was used to identify different groups. Significant variables in the univariate analyses were included in a multivariate Cox regression model to identify the most important prognostic factors. A $\mathrm{p}$ value $<0.05$ was considered statistically significant.

\section{Patient Monitoring}

Patients were called for control the first month after treatment, every 3 months for the first 2 years, every 
6 months until 5 years, and then annually. Detailed head and neck examination and endoscopic evaluation were performed at each control visit. Response evaluation was performed with BT/MR at 1 month after RT and FDG-PET CT at 3 months after RT. If there was a history of cigarette use and clinical indications, thorax CT was required. When local/locoregional relapse or metastasis was detected, treatment decisions were made in multidisciplinary oncology councils.

\section{Results}

The median age of the patients was $50(20-76)$ years. The study included $42(67.7 \%)$ male patients. The most common histopathologic subtype was undifferentiated nonkeratinized squamous cell carcinoma (SCC) $(87.1 \%)$. Others were differentiated nonkeratinized SCC (8.1\%) and keratinized SCC (4.8\%), respectively.

According to the $\mathrm{T}$ stage, 6 (9.7\%) were T1, 37 (59.7\%) were $\mathrm{T} 2,11(17.7 \%)$ were $\mathrm{T} 3$, and $8(12.9 \%)$ were T4. Thirteen $(21.0 \%)$ cases were N0, 11 (17.7\%) cases were $\mathrm{N} 1,27(43.5 \%)$ cases were $\mathrm{N} 2$, and 11
(17.7\%) cases were N3. According to the TNM stage, 4 (6.5\%) patients had stage I, 10 (16.1\%) had stage II, 29 (46.8\%) had stage III, 8 (12.9\%) had stage IVa, and 11 (17.7\%) had stage IVb. Patient characteristics are summarized in Table 1.

The median duration of RT was 52 (42-69) days, and the median time interval between RT was $3(0-$ 15) days. Adjuvant CT was administered to 49 (79\%) cases. Treatment characteristics are summarized in Table 2.

Median overall survival (OS) was 55 (10-134) months, whereas median disease-free survival was 44 (6-129) months. The median duration of local control was 48 (6-129) months. Eleven (17.7\%) patients developed distant metastases. Distant metastases were detected in 6 (9.7\%) patients who had local control. The median weight loss on follow-up during RT was 3 (027) $\mathrm{kg}$. During the follow-up period, $9(14.2 \%)$ cases were diagnosed with hypothyroidism, and 14 (22.5\%) cases died due to disease.

OS was $93 \pm 8$ months for male patients and $126 \pm 5$ months for female patients (univariate analysis $\mathrm{p}=0.042$ and multivariate analysis $\mathrm{p}=0.018$ ) (Fig. 1).

\begin{tabular}{|c|c|c|c|}
\hline Patient characteristics & Criteria & No. of patients & $\%$ \\
\hline \multirow[t]{2}{*}{ Sex } & Male & 42 & 67.7 \\
\hline & Female & 20 & 32.3 \\
\hline \multirow[t]{2}{*}{ Age } & $\leq 50$ & 24 & 38.7 \\
\hline & $>50$ & 38 & 61.3 \\
\hline \multirow[t]{2}{*}{ KPS } & $\leq 70$ & 16 & 25.8 \\
\hline & $>70$ & 46 & 74.2 \\
\hline \multirow[t]{3}{*}{ WHO histologic type } & Keratinizing squamous cell carcinomas & 3 & 4.8 \\
\hline & Differentiated nonkeratinizing carcinomas & 5 & 8.1 \\
\hline & Undifferentiated nonkeratinizing carcinomas & 54 & 87.1 \\
\hline \multirow[t]{4}{*}{ T-status } & $\mathrm{T} 1$ & 6 & 9.7 \\
\hline & $\mathrm{T} 2$ & 37 & 59.7 \\
\hline & T3 & 11 & 17.7 \\
\hline & $\mathrm{T} 4$ & 8 & 12.9 \\
\hline \multirow[t]{4}{*}{$\mathrm{N}$-status } & No & 13 & 21.0 \\
\hline & N1 & 11 & 17.7 \\
\hline & N2 & 27 & 43.5 \\
\hline & N3 & 11 & 17.7 \\
\hline \multirow[t]{5}{*}{ TNM stage } & 1 & 4 & 6.5 \\
\hline & ॥ & 10 & 16.1 \\
\hline & III & 29 & 46.8 \\
\hline & IVa & 8 & 12.9 \\
\hline & $\mathrm{IVb}$ & 11 & 17.7 \\
\hline \multirow[t]{2}{*}{ Tumor diameter } & $\leq 3 \mathrm{~cm}$ & 40 & 64.5 \\
\hline & $>3 \mathrm{~cm}$ & 22 & 35.5 \\
\hline
\end{tabular}

RT: Radiotherapy; WHO: World Health Organization. 
Table 2 Treatment characteristics

\section{Treatment characteristics}

RT dose

Duration of RT

RT break time

Amifostine

$+$

Concomitant chemotherapy

$+$

$50(80.6 \%)$

(no. of patients)

$12(19.4 \%)$

(no. of patients)

Concomitant chemotherapy protocol

Weekly cisplatin $\left(40 \mathrm{mg} / \mathrm{m}^{2}\right)$

$7(11.3 \%)$

Cisplatin every 3 weeks $\left(80-100 \mathrm{mg} / \mathrm{m}^{2}\right)$

$43(69.4 \%)$

Adjuvant chemotherapy

$+$

$49(79.0 \%)$

$13(21.0 \%)$

RT: Radiotherapy.

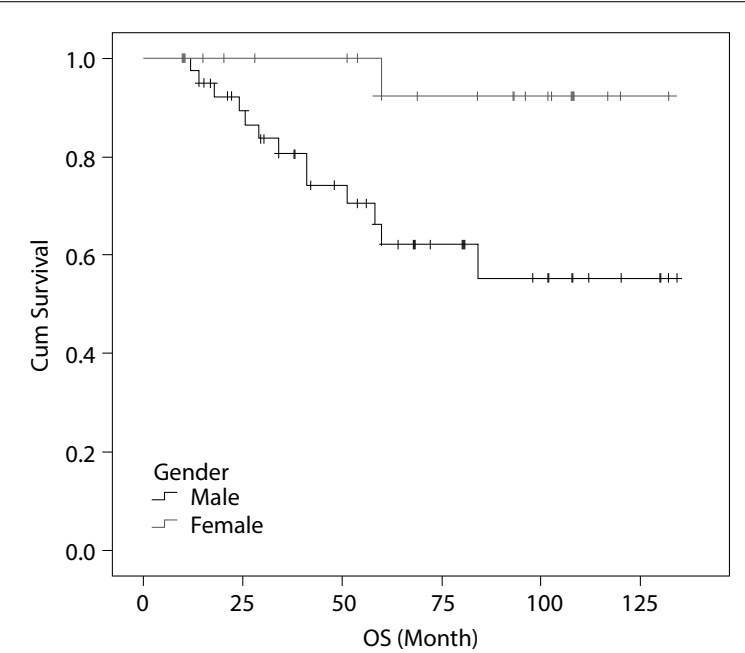

Fig. 1. OS, female versus male patients.

OS was $62 \pm 9$ months in patients with a KPS $\leq 70$ and $119 \pm 6$ months in patients with a KPS $>70$ (univariate analysis $\mathrm{p}=0.002$ and multivariate analysis $\mathrm{p}=0.067$ ) (Fig. 2).

A significant correlation was found between OS and NLR. In our study, a cut-off value of 3 for NLR was accepted because the mean was $3.3 \pm 0.3$ and the median was 2.5 .

Mean OS was $124 \pm 5$ months in an NLR $<3$ cases and $69 \pm 9$ months in an NLR $\geq 3$ cases (univariate analysis $\mathrm{p}=0.008$ and multivariate analysis $\mathrm{p}=0.002$ ) (Fig. 3).

The mean OS was $101 \pm 9$ months in cases with an initial hemoglobin level of $\leq 13 \mathrm{~g} / \mathrm{dl}$ and $107 \pm 8$ months in patients with a hemoglobin level $>13 \mathrm{~g} / \mathrm{dl}$ (univariate analysis $\mathrm{p}=0.498$ and multivariate analysis $\mathrm{p}=0.234$ ).

The mean OS was $108 \pm 7$ months in patients with a baseline platelet value $\leq 250,000 / \mathrm{mm}^{3}$ and $99 \pm 10$ months with a platelet count $>250,000 / \mathrm{mm}^{3}$ (univariate analysis $\mathrm{p}=0.562$ and multivariate analysis $\mathrm{p}=0.206$ ).

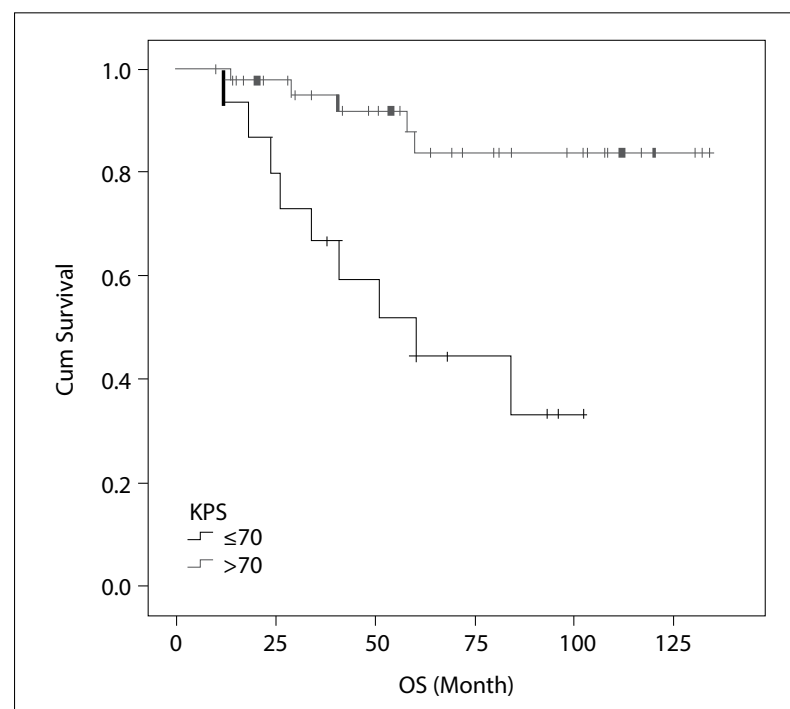

Fig. 2. OS, KPS $>70$ versus $\mathrm{KPS} \leq 70$.

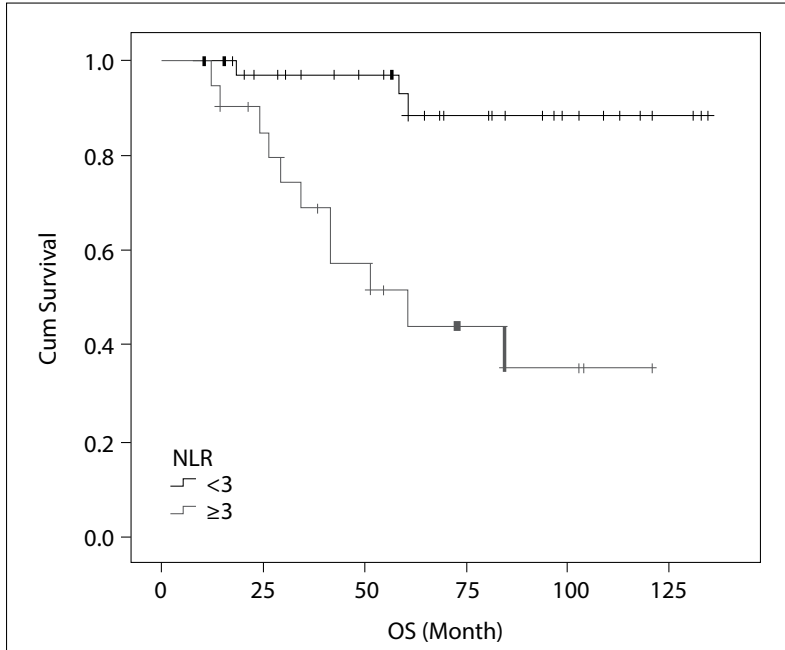

Fig. 3. $O S, N L R<3$ versus $N L R \geq 3$. 
Table 3 The relationship between hematological blood values and overall survival

\begin{tabular}{lcc}
$\begin{array}{l}\text { Blood value } \\
\text { characteristics }\end{array}$ & $\begin{array}{c}\text { Median overall } \\
\text { survival (months) }\end{array}$ & $\begin{array}{c}\text { p } \\
\text { (univariate/ } \\
\text { multivariate) }\end{array}$ \\
\hline $\mathrm{NLR}$ & $124 \pm 5$ & $\mathrm{p}=0.008 / \mathrm{p}=0.002$ \\
$\mathrm{NLR}<3$ & $69 \pm 9$ & \\
$\mathrm{NLR} \geq 3$ & $101 \pm 9$ & $\mathrm{p}=0.498 / \mathrm{p}=0.234$ \\
Hemoglobin & $107 \pm 8$ & \\
Hemoglobin $\leq 13$ & & $\mathrm{p}=0.562 / \mathrm{p}=0.206$ \\
Hemoglobin $>13$ & $108 \pm 7$ & \\
Platelets & $99 \pm 10$ & \\
Platelets $\leq 250.000 / \mathrm{mm}^{3}$ & \\
Platelets $>250.000 / \mathrm{mm}^{3}$ &
\end{tabular}

Table 3 summarizes the relationship between hematological blood values and OS.

Weight loss in the 14 patients who died due to cancer progression was $6.0 \pm 8.5$, whereas it was $3.9 \pm 4.0$ in the living cases (univariate analysis $\mathrm{p}=0.025$ and multivariate analysis $\mathrm{p}=0.006$ ). The mean lactate dehydrogenase (LDH) value was found to be $420.2 \pm 131.2$ in 14 cases who died due to cancer progression, whereas it was $318.7 \pm 117.4$ in living cases (univariate analysis $\mathrm{p}=0.011$ and multivariate analysis $\mathrm{p}=0.063$ ).

The results of the univariate and multivariate analyses of OS are summarized in Table 4.

Patients without distant metastasis were found to have statistically significantly longer survivals, as expected. The mean OS was $42 \pm 6$ months in patients with distant metastases and $121 \pm 5$ months in patients without distant metastases $(\mathrm{p}<0.001)$.

When the relationship between distant metastases and NLR was examined, of the 11 metastatic patients, 7 $(63.6 \%)$ were in the NLR $\geq 3$ group, and $4(36.4 \%)$ were in the NLR $<3$ group $(\mathrm{p}=0.082)$.

The six cases with distant metastasis while locoregional control was present were also distributed evenly between the NLR groups (three cases in the NLR $\geq 3$ groups and three cases in the NLR $<3$ group, $\mathrm{p}=0.661$ ).

NLR status according to some clinical characteristics is shown in Table 5. Mean NLR values according to the TNM stage are shown in Table 6.

Table 5 NLR status according to some clinical characteristics.

\begin{tabular}{lccc} 
Clinical characteristics & Low NLR & High NLR & p \\
\hline $\begin{array}{l}\text { Gender } \\
\text { Female }\end{array}$ & $14(70 \%)$ & $6(30 \%)$ & \\
$\quad$ Male & $25(59.5 \%)$ & $17(40.5 \%)$ & \\
T status & & & 0.575 \\
T1-T2 & $27(62.7 \%)$ & $16(37.3 \%)$ & \\
T3-T4 & $12(63.1 \%)$ & $7(36.9 \%)$ & \\
N status & & & 0.338 \\
N0 & $10(76.9 \%)$ & $3(23.1 \%)$ & \\
N+ & $29(59.1 \%)$ & $20(40.9 \%)$ & \\
Distant metastasis & & & 0.082 \\
Yes & $4(36.4 \%)$ & $7(63.6 \%)$ & \\
No & $35(68.6 \%)$ & $16(31.4 \%)$ & \\
\hline
\end{tabular}

NLR: Neutrophil/lymphocyte ratio.

Table 4 Cox regression analysis: overall survival

\begin{tabular}{|c|c|c|c|c|c|c|}
\hline \multirow[t]{2}{*}{ Variables } & \multicolumn{3}{|c|}{ Univariate } & \multicolumn{3}{|c|}{ Multivariate } \\
\hline & HR & $\% 95 \mathrm{Cl}$ & $\mathbf{p}$ & HR & $\% 95 \mathrm{Cl}$ & $\mathbf{p}$ \\
\hline Male & 8.26 & $1.07-63.50$ & 0.042 & 31.45 & $1.80-547.83$ & 0.018 \\
\hline $\mathrm{KPS} \leq 70$ & 5.63 & $1.88-16.84$ & 0.002 & 3.89 & $0.91-16.65$ & 0.067 \\
\hline T stage & 0.82 & $0.22-2.46$ & 0.733 & --- & & \\
\hline N stage & 0.03 & $0.00-18.36$ & 0.299 & --- & & \\
\hline Tumor diamater & 0.87 & $0.29-2.61$ & 0.806 & 2.32 & $0.50-10.74$ & 0.281 \\
\hline Concomitant chemotherapy & 1.56 & $0.43-5.62$ & 0.492 & 0.72 & $0.06-8.68$ & 0.800 \\
\hline Adjuvant chemotherapy & 1.04 & $0.23-4.67$ & 0.959 & 126.80 & $1.89-8471.12$ & 0.024 \\
\hline Hemoglobin & 1.44 & $0.49-4.19$ & 0.498 & 3.59 & $0.43-29.43$ & 0.234 \\
\hline Platelets & 0.73 & $0.25-2.11$ & 0.562 & 0.20 & $0.03-1.38$ & 0.206 \\
\hline Duration of RT & 1.00 & $0.92-1.09$ & 0.881 & --- & & \\
\hline RT break time & 1.02 & $0.89-1.17$ & 0.762 & --- & & \\
\hline $\mathrm{LDH}$ & 1.00 & $1.00-1.00$ & 0.011 & 1.00 & $1.00-1.01$ & 0.063 \\
\hline$N L R \geq 3$ & 1.19 & $1.04-1.35$ & 0.008 & 0.02 & $0.00-0.25$ & 0.002 \\
\hline Weight loss & 1.11 & $1.01-1.23$ & 0.025 & 1.19 & $1.05-1.34$ & 0.006 \\
\hline
\end{tabular}

KPS: Karnofsky performance status; RT: Radiotherapy; LDH: Lactate dehydrogenase; NLR: Neutrophil/lymphocyte ratio. 
Table 6 NLR values according to the TNM stage

\begin{tabular}{lcc} 
TNM stage & Mean NLR & Standard deviation \\
\hline 1 & 3.13 & 2.343 \\
2 & 2.655 & 1.041 \\
3 & 2.903 & 1.611 \\
4 & 4.446 & 3.417 \\
\hline
\end{tabular}

NLR: Neutrophil/lymphocyte ratio.

Distant metastases were found to be significantly higher in male cases, and all 11 metastatic cases were male patients (Fisher's exact test $\mathrm{p}=0.012$ ).

At diagnosis, distant metastases were more frequent in the KPS $\leq 70$ group (Fisher's exact test $p=0.026$ ). Additional chronic diseases in patients decrease the KPS values of patients. Patients cannot receive synchronous/ adjuvant CT because of comorbidities and secondary low KPS values. It is thought that the increase in the frequency of distant metastases in low KPS patients is due to the lack of CT in their treatment.

The initial hemoglobin level was statistically higher in male patients than in female patients (Fisher's exact test $\mathrm{p}=0.007$ ); $65 \%$ of the female patients had a hemoglobin level $\leq 13$, whereas only $28.6 \%$ of male patients were below this level.

\section{Discussion}

Nasopharyngeal cancer (NPC) is rather radiosensitive, and RT is the main treatment for NPC. NPC's presentation and prognosis are variable. Even patients with the same clinical stage can have very different prognoses. The aim of the present study was to investigate prognostic factors, especially NLR.

Inflammation is considered to play an important role in the development of cancer, and inflammation may be a negative factor affecting OS of patients with cancer.[11] A statistically significant correlation was found between NLR and OS in the present study. In our study, survival rates were found to be lower in patients with an NLR $\geq 3$.

Different cut-off values are available from different studies. Using an NLR limit of 2.7, Sun et al. found that higher NLR values are associated with shorter progression-free survival.[12] In another study of NPC, an NLR value of $\geq 3.6$ was associated with shorter progression-free survival, disease-specific survival, and OS. Compared with early-stage disease, the statistical relationship between high NLR and poor prognosis was found to be stronger in advanced stage disease. [13] In another study of 229 patients with NPC, the NLR threshold value was accepted as 3.6, and the median survival in the high NLR group was 15.3 months, whereas it was 23.5 months in the low NLR group $(\mathrm{p}<0.001)$.[14] In the study conducted by Chen et al. of 211 patients with metastatic NPC, OS was lower in the NLR 5 group (univariate analysis $\mathrm{p}=0.025$ and multivariate analysis $\mathrm{p}=0.019$ ).[15] In a study of 140 patients with non-metastatic NPC, the NLR threshold was accepted as 2.28, with a lower progression-free survival and OS rates in the high NLR group $(\mathrm{p}<0.05)$. [16] In a study of 98 patients with non-metastatic NPC, the NLR limit value was 2.995 , and the treatment failure and recurrence rates were higher in patients in the high NLR group ( $p=0.001)$.[17] A summary of the literature is shown in Table 7. Similarly, NLR is associated with poor prognosis when we examine the literature examples.

Neutrophils, an inflammatory cell type, are thought to be involved in different stages of tumor development through the production of various cytokines, such as oncostatin $M$, hepatocyte growth factor, and transforming growth factor-beta.[18] In addition, neutrophils support tumor angiogenesis and also support the release of angiogenic factors, such as vascular en-

Table 7 Literature summary

\begin{tabular}{lcccl} 
First author/year & Study year & $\begin{array}{c}\text { Number of } \\
\text { patients }\end{array}$ & $\begin{array}{c}\text { The reference } \\
\text { value of NLR }\end{array}$ & Outcomes \\
\hline SUN W, 2015 & $2008-2011$ & 251 & 2.70 & Short PFS $(p=0.001)$ \\
LIAO L.J, 2017 & $2007-2013$ & 180 & 3.6 & Short PFS $(p=0.28)$, OS $(p=0.022)$ and DSS ( $p=0.011)$ \\
JIN Y, 2015 & $2006-2011$ & 229 & 3.6 & Short OS $(p<0.001)$ \\
CHEN C, 2014 & $2005-2011$ & 211 & 5 & Short OS $(p=0.025$ univariate analysis, $p=0.019$ \\
& $2009-2010$ & 140 & 2.28 & multivariate analysis) \\
LU A, 2017 & $2005-2009$ & 98 & 2.995 & Short OS $(p<0.05)$ and PFS $(p<0.05)$ \\
LIEW Y.L, 2017 & $20177^{[17]}$ & $2005)$ & & Short DFS $(p=0.000077)$. \\
\hline
\end{tabular}

PFS: Progression-free survival; OS: Overall survival; DSS: Disease-specific survival; DFS: Disease-free survival; NLR: Neutrophil/lymphocyte ratio. 
dothelial growth factor, angiopoietin-1, and fibroblast growth factor-2.[19,20] On the other hand, lymphocytes are also responsible for removing tumor cells. [21] NPC is usually infiltrated by lymphocytes, such as T helper 17 (Th17) cells. Th17 cells are partially regulated by macrophage migration inhibitory factor, produce high levels of cytokines, including tumor necrosis factor and interferon- $\gamma$, and mediate the antitumor effects.[22]

For this reason, NLR can affect the survival of patients with NPC by affecting the tumor microenvironment and the immune system. Almost all NLR-related studies in cancer have shown a worsening of the prognosis with higher NLR.[14,23-25] Given the results of various investigations, neutrophil and lymphocyte values appear to provide a balance between inflammation and angiogenesis (neutrophils) and protective immunity (lymphocytes). Disruption of this balance in favor of neutrophils can lead to tumor progression by stimulating angiogenesis.

In the present study, deaths due to disease progression were found to be higher in patients with higher weight loss and those with high pretreatment serum $\mathrm{LDH}$. Weight loss is common in the treatment of NPC. In a study evaluating 2399 patients with NPC, $\geq 4.6 \%$ weight loss was evaluated as critical weight loss. Compared with patients without critical weight loss, patients with critical weight loss had significantly lower 5 -year OS $(72.4 \%$ vs. $79.3 \%, \mathrm{p}<0.001)$, failure-free survival $(71.1 \%$ vs. $78.4 \%, \mathrm{p}<0.001)$, and locoregional failure-free survival $(78.1 \%$ vs. $84.8 \%$, $\mathrm{p}<0.001$ ), respectively. In the present study, critical weight loss was accepted as a prognostic factor.[26] There are many studies investigating pretreatment serum LDH levels in NPC. Turen et al. reported the relationship between $\mathrm{LDH}$ and $\mathrm{OS}$ in 61 patients with stage III-IV NPCs. Serum LDH level was found to be higher ( $>460 \mathrm{IU} / \mathrm{l})$ in $24.6 \%$ of the patients. LDH level was found to correlate with poor 4-year OS $(28.5 \% \mathrm{vs.}$ $68.7 \%, \mathrm{p}=0.01)$.[27]

\section{Limitations of the Study}

Our study has limitations. The limitations of the present study include its retrospective and single-centered design and having a small number of patients.

\section{Conclusion}

In the present study, pretreatment NLR was found to be a prognostic factor for nasopharyngeal cancer. More patient-specific, multicenter and prospective studies are needed to use NLR as a marker for nasopharyngeal cancer, similar to EBV DNA.

Peer-review: Externally peer-reviewed.

Conflict of Interest: No conflict of interest was declared by the authors.

Ethics Committee Approval: This study was conducted in accordance with local ethical rules.

Financial Support: No support.

Authorship contributions: Concept - M.A., D.E., A.Ö., S.Ş.; Design - M.A., D.E.; Supervision - M.A., D.E.; Materials - M.A., D.E., A.Ö., S.Ş.; Data collection \&/or processing - M.A., D.E., A.Ö., S.Ş.; Analysis and/or interpretation M.A., D.E., A.Ö., S.Ş.; Literature search - M.A., D.E., S.Ş.; Writing - M.A., D.E., A.Ö., S.Ş.; Critical review - M.A., D.E., A.Ö., S.Ş.

\section{References}

1. Chua MLK, Wee JTS, Hui EP, Chan ATC. Nasopharyngeal carcinoma. Lancet 2016;387(10022):1012-24.

2. Lee AW, Ma BB, Ng WT, Chan AT. Management of Nasopharyngeal Carcinoma: Current Practice and Future Perspective. J Clin Oncol 2015;33(29):3356-64.

3. Sun R, Qiu HZ, Mai HQ, Zhang Q, Hong MH, Li YX, et al. Prognostic value and differences of the sixth and seventh editions of the UICC/AJCC staging systems in nasopharyngeal carcinoma. J Cancer Res Clin Oncol 2013;139(2):307-14.

4. Tang LQ, Chen QY, Fan W, Liu H, Zhang L, Guo L, et al. Prospective study of tailoring whole-body dualmodality [18F]fluorodeoxyglucose positron emission tomography/computed tomography with plasma Epstein-Barr virus DNA for detecting distant metastasis in endemic nasopharyngeal carcinoma at initial staging. J Clin Oncol 2013;31(23):2861-9.

5. Chua M, Whee Sze O, Wee J, Soong Y, Lim D, Tan T. Plasma EBV DNA as a Predictive Biomarker in Patients With Endemic Nasopharyngeal Carcinoma Treated With Induction Chemotherapy and Concurrent Chemoradiation Therapy. Int J Radiat Oncol Biol Phys 2014;90(1):S120-S1.

6. Leung SF, Chan KC, Ma BB, Hui EP, Mo F, Chow KC, et al. Plasma Epstein-Barr viral DNA load at midpoint of radiotherapy course predicts outcome in advanced-stage nasopharyngeal carcinoma. Ann Oncol 2014;25(6):1204-8.

7. Shen L, Zhang H, Liang L, Li G, Fan M, Wu Y, et al. Baseline neutrophil-lymphocyte ratio $(\geq 2.8)$ as a prognostic factor for patients with locally advanced rectal cancer undergoing neoadjuvant chemoradiation. Radiat Oncol 2014;9:295. 
8. Zhao QT, Yang Y, Xu S, Zhang XP, Wang HE, Zhang $\mathrm{H}$, et al. Prognostic role of neutrophil to lymphocyte ratio in lung cancers: a meta-analysis including 7,054 patients. Onco Targets Ther 2015;8:2731-8.

9. Diakos CI, Charles KA, McMillan DC, Clarke SJ. Cancer-related inflammation and treatment effectiveness. Lancet Oncol 2014;15(11):e493-503.

10. McMillan DC. Systemic inflammation, nutritional status and survival in patients with cancer. Curr Opin Clin Nutr Metab Care 2009;12(3):223-6.

11. Shalapour S, Karin M. Immunity, inflammation, and cancer: an eternal fight between good and evil. J Clin Invest 2015;125(9):3347-55.

12. Sun W, Zhang L, Luo M, Hu G, Mei Q, Liu D, et al. Pretreatment hematologic markers as prognostic factors in patients with nasopharyngeal carcinoma: Neutrophil-lymphocyte ratio and platelet-lymphocyte ratio. Head Neck 2016;38 Suppl 1:E1332-40.

13. Liao LJ, Hsu WL, Wang CT, Lo WC, Cheng PW, Shueng PW, et al. Prognostic impact of pre-treatment neutrophil-to-lymphocyte ratio (NLR) in nasopharyngeal carcinoma: A retrospective study of 180 Taiwanese patients. Clin Otolaryngol 2018;43(2):463-469.

14. Jin Y, Ye X, He C, Zhang B, Zhang Y. Pretreatment neutrophil-to-lymphocyte ratio as predictor of survival for patients with metastatic nasopharyngeal carcinoma. Head Neck 2015;37(1):69-75.

15. Chen C, Sun P, Dai QS, Weng HW, Li HP, Ye S. The Glasgow Prognostic Score predicts poor survival in cisplatin-based treated patients with metastatic nasopharyngeal carcinoma. PLoS One 2014;9(11):e112581.

16. Lu A, Li H, Zheng Y, Tang M, Li J, Wu H, et al. Prognostic Significance of Neutrophil to Lymphocyte Ratio, Lymphocyte to Monocyte Ratio, and Platelet to Lymphocyte Ratio in Patients with Nasopharyngeal Carcinoma. Biomed Res Int 2017;3047802.

17. Liew KY, Zulkiflee AB. Neutrophil-lymphocyte ratios in the prognostication of primary non-metastaticnasopharyngeal carcinoma. Braz J Otorhinolaryngol 2018;84(6):764-71.
18. Tecchio C, Scapini P, Pizzolo G, Cassatella MA. On the cytokines produced by human neutrophils in tumors. Semin Cancer Biol 2013;23(3):159-70.

19. Neagoe PE, Brkovic A, Hajjar F, Sirois MG. Expression and release of angiopoietin-1 from human neutrophils: intracellular mechanisms. Growth Factors 2009;27(6):335-44.

20. Tecchio C, Cassatella MA. Neutrophil-derived cytokines involved in physiological and pathological angiogenesis. Chem Immunol Allergy 2014;99:123-37.

21. Basso S, Zecca M, Merli P, Gurrado A, Secondino S, Quartuccio G, et al. T cell therapy for nasopharyngeal carcinoma. J Cancer 2011;2:341-6.

22. Kryczek I, Banerjee M, Cheng P, Vatan L, Szeliga W, Wei $\mathrm{S}$, et al. Phenotype, distribution, generation, and functional and clinical relevance of Th17 cells in the human tumor environments. Blood 2009;114(6):1141-9.

23. He JR, Shen GP, Ren ZF, Qin H, Cui C, Zhang Y, et al. Pretreatment levels of peripheral neutrophils and lymphocytes as independent prognostic factors in patients with nasopharyngeal carcinoma. Head Neck 2012;34(12):1769-76.

24. Ozdemir Y, Akin ML, Sucullu I, Balta AZ, Yucel E. Pretreatment neutrophil/lymphocyte ratio as a prognostic aid in colorectal cancer. Asian Pac J Cancer Prev 2014;15(6):2647-50.

25. Rachidi S, Wallace K, Wrangle JM, Day TA, Alberg AJ, Li Z. Neutrophil-to-lymphocyte ratio and overall survival in all sites of head and neck squamous cell carcinoma. Head Neck 2016;38 Suppl 1:E1068-74.

26.Zeng Q, Shen LJ, Guo X, Guo XM, Qian CN, Wu PH. Critical weight loss predicts poor prognosis in nasopharyngeal carcinoma. BMC Cancer 2016;16:169.

27. Turen S, Ozyar E, Altundag K, Gullu I, Atahan IL. Serum lactate dehydrogenase level is a prognostic factor in patients with locoregionally advanced nasopharyngeal carcinoma treated with chemoradiotherapy. Cancer Invest 2007;25(5):315-21. 